22. Mehta, M. and Sanjay Arora, Soil microbial biomass and activity in salt affected coastal soils under different land uses. In: Proceedings of National Conference on 'Advanced Trends in Applied Sciences and Technology', SES, SICE, Surat, 2012, pp. 433-437.

23. Khursheed, S., Sanjay Arora and Ali, T., Effect of different organic sources on biochemical properties in Typical Inceptisols of Jammu. Prog. Agric., 2012, 12(2), 348-353.

24. Tripathi, S., Chakraborty, A., Chakrabarti, K. and Bandyopadhyay, B. K., Enzyme activities and microbial biomass in coastal soils of India. Soil Biol. Biochem., 2007, 39, 2840-2848.

25. Perucci, P. and Scarponi, L., Effects of the herbicide imazetapir on soil microbial biomass and various soil enzyme activities. Biol. Fertil. Soils, 1994, 17, 237-240.

26. Menon, P., Gopal, M. and Parsad, R., Effects of chlorpyrifos and quinalphos on dehydrogenase activities and reduction of $\mathrm{Fe}^{3}$ in the soils of two semi-arid fields of tropical India. Agric. Ecosyst. Environ., 2005, 108, 73-83.

27. Schuster, E. and Schroder, D., Side-effects of sequentially and simultaneously applied pesticides on non-target soil microorganisms: Laboratory experiments. Soil Biol. Biochem., 1990, 22, 375 383 .

28. Khursheed, S., Arora, S. and Ali, T., Effect of organic sources of nitrogen on rice (Oryza sativa) and soil carbon pools in Inceptisols of Jammu. Int. J. Environ. Pollut. Solu., 2013, 1, 17-21.

ACKNOWLEDGEMENTS. The work was conducted in an interinstitutional (CSSRI-NCIPM) collaborative project by a multidisciplinary team. We thank ICAR for extending funding support through NCIPM and Director, CSSRI, Karnal and Head, RRS, Lucknow for providing necessary facilities.

Received 2 September 2015; revised accepted 3 November 2018

doi: $10.18520 / \mathrm{cs} / \mathrm{v} 116 / \mathrm{i} 4 / 643-649$

\section{Enhancing the anti-tyrosinase activity of a hypersaline Kitasatospora sp. SBSK430 by optimizing the medium components}

\author{
Michelle S. Fernandes and Savita Kerkar* \\ Department of Biotechnology, Goa University, Goa 403 206, India
}

Tyrosinase inhibitors from natural resources have been gaining importance in pharmaceutical and horticultural applications. A full factorial central composite design was used to study the interactive effect of three variables, i.e. D-mannitol, yeast extract and sodium chloride of the fermentation medium for maximizing anti-tyrosinase activity $\mathbf{( 7 5 . 5 \% )}$ of a hypersaline actinobacteria, Kitasatospora sp. SBSK430. A quadratic model was found to fit the anti-tyrosinase activity

*For correspondence. (e-mail: drsavitakerkar@gmail.com)
$\left(R^{2}=0.948\right)$. Response surface analysis revealed that the optimum values of the medium components were $15 \mathrm{~g} / \mathrm{l}$ D-mannitol, $5.6 \mathrm{~g} / \mathrm{l}$ yeast extract and $1.2 \mathrm{~g} / \mathrm{l}$ sodium chloride. Tyrosinase inhibition activity was enhanced 1.1-fold, using this approach.

Keywords: Actinobacteria, anti-tyrosinase, fermentation medium, hypersaline, Kitasatospora sp.

ENZYMES are vital proteins involved in regulating various biochemical cycles in a biological system. They are also responsible for various reactions, and associated with several human disorders. Apart from enzymes, enzyme inhibitors have been extensively examined; not only to study the structure of the enzyme and its mechanism, but also for its application in other sectors such as agriculture $^{1,2}$, cosmetics ${ }^{2,3}$ and pharmaceuticals ${ }^{2,4}$. The enzyme tyrosinase (EC 1.14.18.1) has been gaining importance due to its widespread applications. It is a key enzyme responsible for the production of melanin, causing hyperpigmentation in the skin and undesirable browning of fruits and vegetables 5 . Thus, the search for a novel tyrosinase inhibitor is important.

Marine microorganisms are metabolically and physiologically different from terrestrial ones, owing to extreme environments such as high temperature and salinity, and low organic matter; thereby providing a potential source for novel and diverse compounds ${ }^{6}$. Among bacteria, actinobacteria are a renowned source of bioactive natural compounds with applications in medicine, agriculture and industry. They produce diverse secondary metabolites such as enzymes ${ }^{7,8}$, antibiotics ${ }^{9,10}$, probiotics $^{8}$, biosurfac$\operatorname{tants}^{7}$ and enzyme inhibitors ${ }^{11,12}$; Streptomyces being the major candidate ${ }^{13-15}$. Imada ${ }^{12}$ reported different types of enzyme inhibitors from marine actinobacteria, viz. glucosidase, $N$-acetyl-beta-D-glucosaminidase, pyroglutamyl peptidase and amylase inhibitors. Tyrosinase inhibitors have been reported from various natural and synthetic sources, highlighting their industrial relevance $e^{2,3,16-18}$. Researchers are turning towards metabolites from natural sources for various applications. Fernandes and Kerkar ${ }^{19}$ have reviewed tyrosinase inhibitors produced by microorganisms; with major inhibitors reported from fungi and Streptomyces species ${ }^{19}$.

The genus Kitasatospora, classified under Actinobacteria, has been reported as a producer of many bioactive compounds ${ }^{20-23}$. There are several reports of Kitasatospora producing novel bioactive compounds showing different activities $^{24}$. The genus is reported to exhibit various activities which include antimicrobial activity ${ }^{21,25,26}$, proteosome inhibitor ${ }^{23,27}$ and proteinase inhibitor ${ }^{28,29}$. Therefore, this genus could be the source of a new compound of biological importance.

Growth improvement of the organism is possible by manipulating its culturing conditions, in terms of nutritional and physical parameters. Various regulatory 
mechanisms exist in microorganisms that control the production of metabolites by fermentation. Complete knowledge of optimal conditions is required for maximum fermentation leading to the production of the concerned metabolite by actinobacteria. Thus, medium composition plays a central role in the process with respect to efficiency and economics. It influences the growth, metabolism, product yield and activity of the culture $^{15}$. With regard to this, our next objective was aimed to optimize the culture conditions for higher yield of the metabolite. The conventional method for optimization includes a single factor manipulation maintaining the other factors constant. However, this method is timeconsuming, unreliable and does not depict the interaction of all the factors involved in the production and activity of the product. These limitations can be eliminated by a statistical approach using response surface methodology which could improve yield and reduce cost, process unreliability and time. Thus our study is aimed at optimizing the fermentation medium for enhancing the anti-tyrosinase activity of a hypersaline Kitasatospora sp. using a statistical approach.

Strain SBSK-430 isolated from marine saltern of Goa, India was identified as Kitasatospora sp. by $16 \mathrm{~S}$ rRNA sequencing (GenBank accession no. KJ081549.1), and observed to have anti-tyrosinase activity.

The basic medium used for optimization consisted of D-mannitol $10 \mathrm{~g} / 1$; yeast extract $2 \mathrm{~g} / \mathrm{l}$; dipotassium phosphate $1 \mathrm{~g} / \mathrm{l}$; sodium chloride $1 \mathrm{~g} / \mathrm{l}$; magnesium sulphate $1 \mathrm{~g} / 1$; calcium carbonate $4 \mathrm{~g} / 1$; ferrous sulphate $0.001 \mathrm{~g} / \mathrm{l}$; manganous chloride $0.001 \mathrm{~g} / 1$; zinc sulphate $0.001 \mathrm{~g} / 1$, and $\mathrm{pH}$ adjusted to $7.0 \pm 2$. Kitasatospora $\mathrm{sp}$. SBSK-430 was cultured in a flask $(150 \mathrm{ml})$ with $50 \mathrm{ml}$ medium on a rotary shaker $(120 \mathrm{rpm})$ at $37^{\circ} \mathrm{C}$. All the chemicals were procured from Hi-Media, India.

Anti-tyrosinase activity was analysed by spectroscopy as described by Chang and Tseng ${ }^{30}$, with modifications. The growth of SBSK430 was also monitored by determining the dry cell weight (DCW). The culture was centrifuged at $8000 \mathrm{rpm}$ for $15 \mathrm{~min}$ and transferred to a pre-weighed filter paper. The biomass was dried at $55^{\circ} \mathrm{C}$ overnight, weighed and expressed as milligrams per milliliter $(\mathrm{mg} / \mathrm{ml})^{31}$. The cell-free supernatant $(200 \mu \mathrm{l})$ of the cultured isolate was collected and used for the assay. The supernatant was added to $0.2 \mathrm{mM}$ L-tyrosine $(800 \mu \mathrm{l})$ and the reaction was initiated with $20 \mu \mathrm{l}$ of tyrosinase enzyme (EC 1.14.18.1; Sigma-Aldrich). The assay mixture was incubated at $30^{\circ} \mathrm{C}$ for $30 \mathrm{~min}$; an increase in absorbance at $475 \mathrm{~nm}$ was monitored and the per cent inhibition of tyrosinase activity was calculated as follows

$\%$ Inhibition $=[(A-B) / A] \times 100$,

where $A$ is the absorbance at $475 \mathrm{~nm}$ with sterile broth (control) and $B$ is the absorbance at $475 \mathrm{~nm}$ with the tested sample.
To screen the most influential parameters for optimization of anti-tyrosinase activity by Kitasatospora sp. SBSK-430, various process variables such as cultivation time (up to 18 days), temperature $\left(10-50^{\circ} \mathrm{C}\right)$, initial $\mathrm{pH}$ (2.0-9.0) of the medium, sodium chloride (0-8\%), calcium carbonate $(0-0.5 \%)$, dipotassium phosphate $(0-$ $0.2 \%$ ), carbon and nitrogen sources were analysed using the one-factor-at-a-time (OFAT) approach. Each factor assessed was incorporated further in subsequent experiments keeping other factors constant, unless otherwise stated.

Further, response surface methodology (RSM) approach was used to study the interaction among the three influencing variables selected from OFAT, i.e. carbon source: D-mannitol (A), nitrogen source: yeast extract (B) and sodium chloride (C) on anti-tyrosinase activity by Kitasatospora sp. SBSK-430. The other components of the basal medium were kept constant, varying only three influential factors. The experimental design was analysed by Design Expert 6.0 (Stat-Ease, Minneapolis, USA). The design was used to identify the effect of these variables on each other for maximizing production of the tyrosinase inhibitor, thereby maximizing its anti-tyrosinase activity and thus determining the optimum fermentation conditions. In addition, it was also used to access whether the enzyme inhibitor production was growth-associated. According to this design, 20 experiments were performed in triplicate, containing six replicate controls at the centre point. In this study, three key factors with three concentration levels were adopted.

The comparison of anti-tyrosinase activity with ten different carbon and nitrogen sources respectively, was carried out using OFAT approach. D-mannitol and yeast extract resulted in the highest activity compared to the other nine carbon and nitrogen sources.

RSM consists of an empirical technique for developing, enhancing and optimizing processes influenced by variable responses. It generates a mathematical model defining the effect of independent variables, alone or in combination, on the fermentation process ${ }^{32,33}$. Prior knowledge of the process and its variables is important to obtain a realistic model ${ }^{34}$. To accomplish this, the effect of different factors such as $\mathrm{pH}$, temperature, carbon and nitrogen sources, calcium carbonate, sodium chloride and dipotassium phosphate was evaluated using the OFAT approach. Tyrosinase inhibitory activity was found to increase by 1.25 -fold (71\%).

To the best of our knowledge, there are no previous reports on utilizing D-mannitol as a carbon source for the production of anti-tyrosinase activity by actinobacteria. Other factors such as concentration of calcium carbonate and dipotassium phosphate did not have a considerable effect on the activity. D-mannitol, yeast extract and sodium chloride were found to be the most influential factors. The $\mathrm{pH}$, temperature and concentration of calcium carbonate and dipotassium phosphate were kept 
RESEARCH COMMUNICATIONS

Table 1. Central composite experimental design with biomass and anti-tyrosinase activity

\begin{tabular}{rccccc}
\hline Run & A & B & C & Biomass $(\mathrm{mg} / \mathrm{ml})$ & Anti-tyrosinase activity $(\%)$ \\
\hline 1 & -1 & -1 & -1 & 4.2 & 0.0 \\
2 & -1 & +1 & +1 & 6.0 & 5.9 \\
3 & -1 & +1 & -1 & 5.7 & 43.9 \\
4 & +1 & +1 & -1 & 6.7 & 19.3 \\
5 & 0 & +1 & 0 & 6.5 & 41.9 \\
6 & -1 & -1 & +1 & 4.8 & 10.0 \\
7 & 0 & 0 & +1 & 5.5 & 49.0 \\
8 & +1 & -1 & +1 & 6.9 & 49.5 \\
9 & 0 & 0 & 0 & 5.2 & 65.0 \\
10 & 0 & 0 & -1 & 4.8 & 34.9 \\
11 & 0 & -1 & 0 & 5.6 & 38.6 \\
12 & +1 & 0 & 0 & 6.6 & 54.9 \\
13 & 0 & 0 & 0 & 6.3 & 70.0 \\
14 & -1 & 0 & 0 & 5.5 & 46.0 \\
15 & 0 & 0 & 0 & 6.4 & 50.0 \\
16 & +1 & -1 & -1 & 6.9 & 10.0 \\
17 & +1 & +1 & +1 & 7.9 & 10.0 \\
18 & 0 & 0 & 0 & 6.2 & 70.0 \\
19 & 0 & 0 & 0 & 5.9 & 58.0 \\
20 & 0 & 0 & 0 & 5.9 & 72.0 \\
\hline
\end{tabular}

Table 2. ANOVA for the selected quadratic model

\begin{tabular}{lrrrrr}
\hline Source & Sum of squares & Degree of freedom & Mean squares & $F$-value & $p>F$ \\
\hline Model & $9,707.81$ & 9 & 1078.65 & 20.26 & $<0.0001$ \\
Residual & 532.48 & 10 & 53.25 & & \\
Lack of fit & 163.65 & 5 & 32.73 & & \\
Pure error & 368.83 & 5 & & & \\
Total & $10,240.29$ & & & & \\
\hline
\end{tabular}

constant throughout the experiment, since they had no major effect on anti-tyrosinase activity. Lim and $\mathrm{Kim}^{35}$ reported the influence of yeast extract on tyrosinase inhibitory activity by Lactobacillus $\mathrm{sp}^{35}$.

Based on the most influential variables identified by OFAT, a central composite design (CCD) was proposed for enhancing the anti-tyrosinase activity depicting the actual responses and biomass (Table 1). Table 1 suggests that the increase in anti-tyrosinase activity by SBSK 430 is not growth-associated. The model adequacy was tested and analysis of variance suggested that the model was significant with $F$-value of 20.26 and a very low probability value $>0.0001$ (Table 2 ). The parameters with significant effect were also identified using Fisher's test for analysis of variance (ANOVA). In addition, the goodness-of-fit of the model was evaluated by $R^{2}$ value $\left(R^{2}=0.948\right)$ indicating that the model does not explain only $0.01 \%$ of the total variations. The predicted $R^{2}$ value of 0.8606 was in reasonable agreement with the adjusted $R^{2}$ value of 0.9012 . A high adjusted $R^{2}$ value also supports the significance of the model, and substantiates a good correlation between the individual factors ${ }^{33}$. A low value of the coefficient of variation $(\mathrm{CV}=18.27 \%)$ indicates better precision and reliability of the experiment.
Adequate precision measures the signal-to-noise ratio; a ratio of 12.516 indicates an adequate signal, suggesting that the model can be used to navigate the design space. The lack-of-fit $F$-value of 0.44 implies the lack-of-fit is not significant relative to the pure error, indicating that the model is fit. There is an $80.4 \%$ chance that this large lack-of-fit $F$-value could occur due to noise.

RSM generated the following regression equation with empirical relationship between D-mannitol, yeast extract, sodium chloride and anti-tyosinase activity

$$
\begin{aligned}
Y & =72.09+3.79 * A+1.29 * B+1.63 * C-8.75 * A^{*} B \\
& +7.27 * A^{*} C-12.10 * B^{*} C-8.53 * A^{2}-18.73 * B^{2} \\
& -17.03 * C^{2}
\end{aligned}
$$

where $Y$ is the response (anti-tyrosinase activity) and $A, B$ and $C$ are coded values of the variables D-mannitol, yeast extract and sodium chloride respectively.

The significance of each coefficient was evaluated by $F$-value and $P$-value (Table 3 ) where large $F$-value and Prob $>F$ less than 0.05 indicate that the model terms are significant ${ }^{32,33}$. In this experiment, it implies that quadratic 

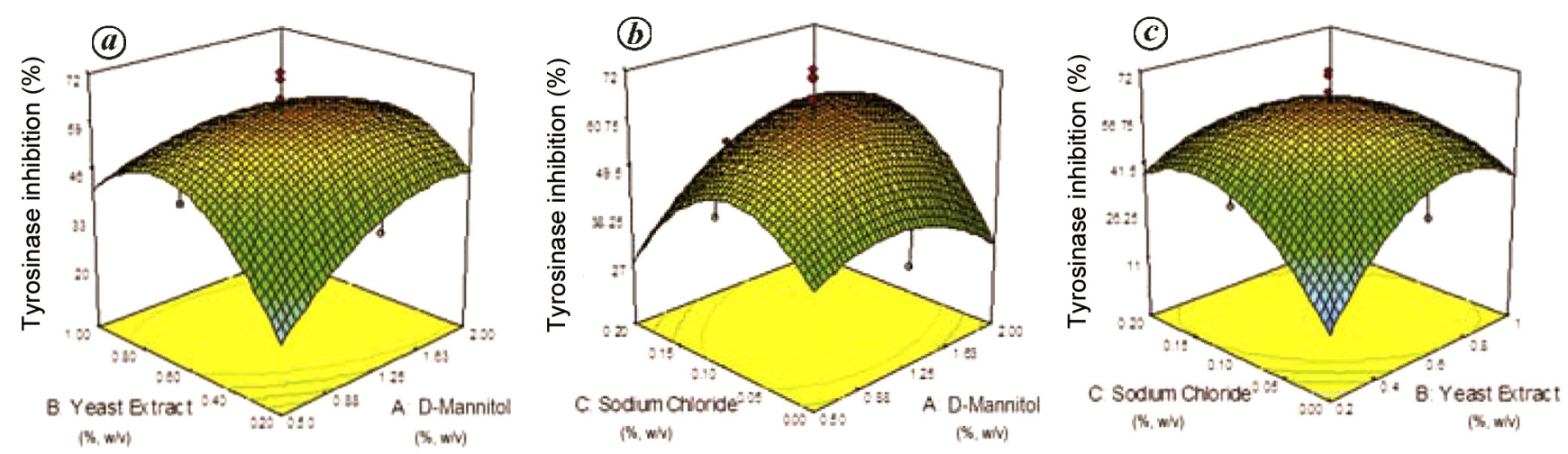

Figure 1. Surface plots of anti-tyrosinase activity: $\boldsymbol{a}-\boldsymbol{c}$, Effect of D-mannitol and yeast extract $(\boldsymbol{a})$, D-mannitol and sodium chloride (b) and sodium chloride and yeast extract $(\boldsymbol{c})$ on tyrosinase inhibitor production.

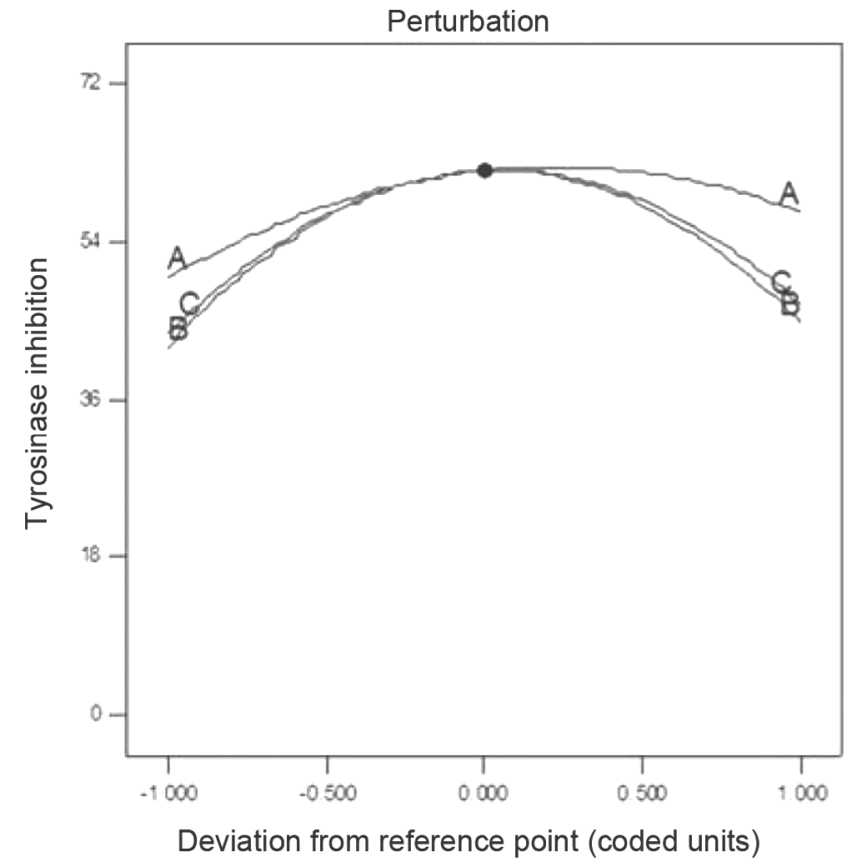

Figure 2. Perturbation graph showing the effect of each independent variable (D-mannitol, yeast extract and sodium chloride) on tyrosinase inhibitor production.

and their interactive effect of yeast extract and sodium chloride are more significant than the other factors. Thus, they can be used as limiting nutrients, and alteration in their concentration can alter the product yield. In addition, the interactive effect of D-mannitol with yeast extract as well as sodium chloride was found to be significant. However, values greater than 0.1 indicates that the model terms are not significant.

The 3D response surface is the graphical representation of the regression equation, indicating the interaction of the factors with the response (Figure 1). Each contour curve in the graph represents a number of combinations of two influencing variables with the other being constant; with maximum predicted value confined in the
Table 3. Result of regression analysis of experimental design

\begin{tabular}{lrcc}
\hline Source & Mean square & $F$-value & Prob $>F$ \\
\hline Model & 9707.81 & 20.26 & $<0.0001$ \\
A & 143.64 & 2.70 & 0.1315 \\
B & 16.64 & 0.31 & 0.5884 \\
C & 26.57 & 0.50 & 0.4961 \\
AB & 612.50 & 1150 & 0.0069 \\
AC & 423.40 & 7.95 & 0.0182 \\
BC & 1171.28 & 22.00 & 0.0009 \\
$\mathrm{~A}^{2}$ & 200.18 & 3.76 & 0.0812 \\
$\mathrm{~B}^{2}$ & 964.92 & 18.12 & 0.0017 \\
$\mathrm{C}^{2}$ & 797.73 & 14.98 & 0.0031 \\
\hline
\end{tabular}

smallest ellipse. Figure $1 a$ describes the effect of Dmannitol and yeast extract on enhancing anti-tyrosinase activity, sodium chloride being fixed at the middle level. The anti-tyrosinase activity increases with increase of both the components. Figure $1 b$ and $c$ also shows a similar trend. In addition, sodium chloride above $1.5 \mathrm{~g} / 1$ showed a decrease in activity, with increasing concentration of D-mannitol (Figure $1 b$ ). Perturbation graph (Figure 2) compares the effect of every factor on a particular point using space design. Figure 2 suggests that all three variables show significant mutual interaction with each other. The model predicts that the maximum antityrosinase activity $(72.8 \%)$ can be obtained using $15 \mathrm{~g} / 1$ D-mannitol, $5.6 \mathrm{~g} / 1$ yeast extract and $1.2 \mathrm{~g} / 1$ sodium chloride. Verification of the results was carried out by the shake flask method and maximum activity was found to be $75.5 \%$. Thus, the model prediction is in close agreement with the experimental value.

Several studies have been carried out with respect to tyrosinase inhibitors from natural sources and their application in post-harvest technology as well as skin depigmentation. Thus, optimizing the production of a potent tyrosinase inhibitor is crucial for its application in largescale production. This is the first report of medium optimization for anti-tyrosinase activity production by Kitasatospora sp. using response surface methodology; 


\section{RESEARCH COMMUNICATIONS}

with 1.1-fold increase in activity compared to the OFAT approach. Thus, a statistical-based approach is an effective tool for medium optimization for anti-tyrosinase activity; it is also relatively simple, efficient and timesaving.

1. Terashita, T., Kono, M. and Murao, S., Promoting effect of S-PI on fruiting of Lentinus edodes. Trans. Mycol. Soc. Jpn., 1980, 21, $137-140$.

2. Kim, Y. J. and Uyama, H., Tyrosinase inhibitors from natural and synthetic sources: structure, inhibition mechanism and perspective for the future. Cell Mol. Life Sci., 2005, 62, 1707-1723.

3. Lin, J. W., Chiang, H. M., Lin, Y. C. and Wen, K. C., Natural products with skin-whitening effects. J. Food Drug Anal., 2008, 16, $1-10$.

4. Bode, W. and Huber, R., Natural protein proteinase inhibitors and their interaction with proteinases. Eur. J. Biochem., 1992, 204, 433-451.

5. Martinez, M. V. and Whitaker, J. R., The biochemistry and control of enzymatic browning. Trends Food Sci. Technol., 1995, 6, 195200.

6. Okami, Y. and Okazaki, T., Studies on marine microorganisms. (1) Isolation from the sea. J. Antibiot., 1976, 25, 456-460.

7. Ballav, S., Dastagar, S. G. and Kerkar, S., Biotechnological significance of actinobacterial research in India. Recent Res. Sci. Technol., 2012, 4, 31-39.

8. Manivasagan, P., Venkatesan, J., Sivakumar, K. and Kim, S. K., Marine actinobacterial metabolites: current status and future perspectives. Microbiol. Res., 2013, 168, 311-332.

9. Sosio, M., Bossi, E., Bianchi, A. and Donadio, S., Multiple peptide synthetase gene clusters in actinomycetes. Mol. Gen. Genet., 2000, 264, 213-221.

10. Bently, S. D., Chater, A. M., Cerdeno-Tarranga, C. and Thomson, N. R., Complete genome sequence of the model actinomycete Streptomyces coelicolor A3 (2). Nature, 2002, 417, 141-147.

11. Bull, A. T., Ward, A. C. and Goodfellow, M., Search and discovery strategies for biotechnology: the paradigm shift. Mol. Biol. Rev., 2000, 64, 573-606.

12. Imada, C., Enzyme inhibitors and other bioactive compounds from marine actinomycetes. Antonie Van Leeuwenhoek., 2005, 87, 5963.

13. Umezawa, H., Enzyme Inhibitors of Microbial Origin, University Park Press, Baltimore, USA, 1972.

14. Dharmaraj, S., Marine streptomyces as a novel source of bioactive substances. World J. Microbiol. Biotechnol., 2010, 26, 2123-2139.

15. Subramani, R. and Aalbersberg, W., Marine actinomycetes: an ongoing source of novel bioactive metabolites. Microbiol. Res., 2012, 167, 571-580.

16. Chang, T., An updated review of tyrosinase inhibitors. Int. J. Mol. Sci., 2009, 10, 2440-2475.

17. Loizzo, M. R., Tundis, R. and Mecnichini, F., Natural and synthetic tyrosinase inhibitors as antibrowning agents: an update. Compr. Rev. Food Sci. Food Saf., 2012, 11, 378-398.

18. Chen, C., Lin, L., Yang, W., Bordon, J. and Wang, H., An updated organic classification of tyrosinase inhibitors on melanin biosynthesis. Curr. Org. Chem., 2015, 19, 4-18.

19. Fernandes, M. S. and Kerkar, S., Microorganisms as a source of tyrosinase inhibitors: a review. Ann. Microbiol., 2017, 67, 343358

20. Takahashi, Y., Seino, A., Iwai, Y. and Omura, S., Taxonomic study and morphological differentiation of an actinomycete genus, Kitasatospora. Zentralbl. Bakteriol., 1999, 289, 265-284.

21. Yoon, T. M., Kim, J. W., Kim, J. G., Kim, W. G. and Suh, J. W., Talosins A and B: new isoflavonol glycosides with potent antifungal activity from Kitasatospora kifunensis MJM341. J. Antibiot., 2006, 59, 633-639.
22. Shi, N., Lu, C., Ho, C. C. and Shen, Y., Kitasatodine and kitasatopenoid from Kitasatospora sp. H6549, a new strain from Malaysia. Rec. Nat. Prod., 2013, 7, 1-5.

23. Gill, K. A., Berrue, F., Arens, J. C., Carr, G. and Kerr, R., Cystargolides, 20S proteasome inhibitors isolated from Kitasatospora cystarginea. J. Nat. Prod., 2015, 78, 822-826.

24. Takahashi, Y. and Omura, S., Isolation of new actinomycete strains for the screening of new bioactive compounds. J. Gen. Appl. Microbiol., 2003, 49, 141-154.

25. Chung, Y. R., Sung, K. C., Mo, H. K., Son, D. Y., Nam, J. S., Chun, J. and Bae, K. S., Kitasatospora cheerisanensis sp. nov., a new species of the genus Kitasatospora that produces an antifungal agent. Int. J. Syst. Bacteriol., 1999, 49, 753-758.

26. Yang, S. et al., New antibiotic Sch 725424 and its dehydration product Sch 725428 from Kitasatospora sp. J. Antibiot., 2005, 58, 192-195.

27. Momose, I. et al., Tyropeptins A and B, new proteasome inhibitors produced by Kitasatospora sp. MK993-dF2. I. Taxonomy, isolation, physio-chemical properties and biological activities. J. Antibiot., 2001, 54, 997-1003.

28. Maeda, M., Kodama, T., Iwasawa, N., Higuchi, N. and Amano, N., Production of aspartic proteinase inhibitor by Kitasatospora kyotoensis. European Patent EP 0316907 A2, 1989.

29. Oda, K., Fukuda, Y., Murao, S., Uchida, K. and Kainosho, M., A novel proteinase inhibitor, tyrostatin, inhibiting some pepstatininsenstive carboxyl proteinase. Agric. Biol. Chem., 1989, 53, 405415 .

30. Chang, T. and Tseng, M., Preliminary screening of soil actinomycetes for anti-tyrosinase activity. J. Mar. Sci. Technol., 2006, 14, 190-193.

31. Singh, L. S., Mazumder, S. and Bora, T. C., Optimisation of process parameters for growth and bioactive metabolite produced by a salt-tolerant and alkaliphilic actinomycete, Streptomyces tanashiensis strain A2D. J. Mycol. Méd., 2009, 19, 225-233.

32. Anjum, M. F., Tasadduq, I. and Al-Sultan, K., Response surface methodology: a neural network approach. Eur. J. Oper. Res., 1997, 101, 65-73.

33. Bas, D. and Boyac, I. S., Modeling and optimization I: usability of response surface methodology. J. Food Eng., 2007, 78, 836-845.

34. Akhnazarova, S. and Kefarov, V., Experiment Optimization in Chemistry and Chemical Engineering, Mir Publishers, Moscow, 1982.

35. Lim, S. D. and Kim, K. S., Optimization of tyrosinase inhibitory activity in the fermented milk by Lactobacillus plantarum M23. Korean J. Food Sci. An., 2012, 32, 678-684.

ACKNOWLEDGEMENTS. We thank the Head, Department of Biotechnology, Goa University for providing the necessary facilities. This study was funded by the University Grant Commission Maulana Azad National Fellowship (MANF-2012-13-CHR-GOA-12673) to M.S.F.

Received 28 March 2018; revised accepted 13 November 2018

doi: $10.18520 / \mathrm{cs} / \mathrm{v} 116 / \mathrm{i} 4 / 649-653$ 